\title{
Communication Students' Skills as a Tool of Development Creativity and Motivation in Geometry
}

\author{
Edita Smieskova
}

Department of Mathematics, Constantine the Philosopher University in Nitra, Slovak Republic

Copyright $\subset 2017$ by authors, all rights reserved. Authors agree that this article remains permanently open access under the terms of the Creative Commons Attribution License 4.0 International License

\begin{abstract}
Often solved problems are problems of students' motivation in the process of teaching and learning. Some authors see the solution in creation a more space to students' creativity in teaching and learning. It is the aim of modern pedagogic and humanistic education, too. The submitted study aims to present possibility of how to teach geometric constructions in connection with real life tasks. The topic Geometric constructions give us space to teach mathematics in interesting way and offer students to be creative. The creative tasks are those tasks which are unknown for students and their content is surprising and nontraditional. We will prepare lesson activities according to official Slovak document entitled National Program of Education. Communication skills and ability to collaborate of students' will be factors of their success in the prepared lesson. Students have to solve problems where do not exist one solution and their content relates to interdisciplinary between geometry and fine arts. For evaluation of students' solutions will be used an implicative analysis with statistical software C.H.I.C. (Classification Hérarchique Implicative et Cohésitive).
\end{abstract}

Keywords Communication in Mathematics, Creativity, Geometry, Ornaments

\section{Introduction}

How to teach mathematics better? An answer to this question is not unequivocal. Nowadays, math education requires understanding from many other disciplines of a general education. In modern educational theories the necessity of students' activity during lessons is highlighted. [1]

Why is a communication and students' discussion in mathematics lessons so important? Mathematical communication is an essential process for learning mathematics because through communication, students reflect upon, clarify and expand their ideas and understandings of mathematical arguments. [2]
Jurcova [3] writes about the communication in a problem solving as a tool of development creative skills and abilities of human being.

Moreover, a creativity is an essential feature of personality that is used in everyday life. Creativity allows us to be flexible when dealing with real life situations. Mathematical education should be seen as one of opportunities for a students' creativity development, although the creativity is not traditionally associated with mathematics. [4]

In this paper we focused on the practical use of geometric constructions in a school mathematics aiming to enhance students' motivation and creativity through the communication in a mathematical lesson.

\section{Theoretical Framework}

Educators present in [5], that communication of mathematical ideas helps students to clarify and solidify their understanding of mathematics. The communication can be realized in a written and oral form. In [6] is define an oral and written communication. Oral communication includes talking, listening, questioning, explaining, defining, discussing, describing, justifying, and defending. When students participate in these actions in an active, focused, and purposeful way, they are furthering their understanding of mathematics. Written communication enables students to think about and articulate what they know. Mathematical writing also provides evidence of students' mathematical understanding. Before beginning any writing task, students need experiences in expressing their ideas orally, as well as listen to the ideas of others. The quality of a written product is significantly improved by the opportunity to participate in a class dialogue before writing. Students develop a confidence in themselves as mathematics learners, they should use the communication to generate and share ideas. Also teachers can do a better monitoring of their progress.

Ponte in [7] stated that an open problem was used for encouraging the communication in a classroom. Students had an opportunity to communicate and carry on a discussion about strategies for solving various problems. This kind of 
teaching processes requires a look at a language in mathematics education. According to Inprasitha in [8] open-ended approaches have four steps: posing open-ended problems situation, student's self-learning, class discussion and summary with a connection. Every step shows that the communication helps students to learn mathematics.

Students develop their mathematical communication in different ways. Examples according to Slovak curriculum:

- making mathematics accessible for all students;

- coaching for student success in mathematics;

- learning mathematics within contexts;

- $\quad$ understanding geometric figures.

In the article we analyse the activity which was realized with pre-service mathematics teachers (19-21 years old) and with the students at a secondary school (17-18 years old). Our objectives were:

- developing students' communication abilities and skills in mathematics lesson through construction of ornaments;

- collaborating of students together;

- developing students' creativity in finding of ways ornaments' constructions.

The activities presented in the article and the research brings together concepts and principles of the theory of didactical situations and the analysis of methods of a problem solving processes. A framework to this approach is based on the works Brousseau [9] and Sierpinska \& Kilpatrick [10]. We apply the principles of this theory confirming the importance of the analysis a-priori, and a-posteriori quantitative analysis of results.

\section{Methodology and the lesson description}

The activity was realized in September 2015 within two lessons with 16 students of the Mathematics Teacher Training Study Program and 12 students of High School of Fine Arts. We aimed to what the communication skills students have in the lesson problem from Geometry. The second aim was to know what kinds of creativity they used in the lesson problem. We will describe the activity of the first lesson, which took the time of 45 minutes to both groups of students.

Next, we describe the organization of the first lesson. We divided the lesson into two parts. The duration of the first part was 20 minutes. We divided the students to two big groups of the same size. These groups of students set on the opposite sides of the classroom. Students in the groups received different types of worksheets. One group got a worksheet with ornaments of a meander (two types of a meander), for now we label them as student A and student B with ornament 1 and the second group got a worksheet with flower ornaments (two types of a flower ornament) and we label them as student $\mathrm{C}$ and student $\mathrm{D}$ with ornament 2 (fig. 1). The worksheets were distributed in such way that students in the first group did not see the worksheets of students in the second group.

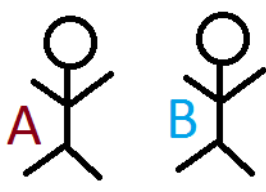

ornament 1

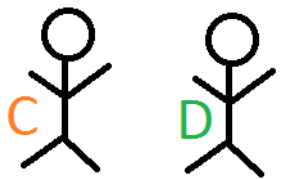

ornament 2
Figure 1. Two groups of students.

Students in the first group had to write instructions of a meander's construction (ornament1). Also students of the second group had to write instructions of a flower ornament's construction (ornament2). We asked them just to write short and clear instructions. Everybody has finished his work after 20 minutes. We continued with a second part of the lesson. Now students worked in pairs (fig. 2). In each pair there was one student with the meander's construction and one with the flower ornament. The student A set at a desk and the student D set turned back to him. The student A who set by back to student $\mathrm{D}$ was dictated his instructions to him (they set in tandem). The student D drew the meander's ornament (ornament 1) according to the instructions of the student A. Student A did not see what student D was drawing and so he had to be careful in his instructions. After that students changed. So, the student A was drawing a flower ornament (ornament 2) according to the instructions of the student D. At the end of the activity, students showed to each other their creations. Then they proved the correction of their steps. If the ornaments were not the same they had to look for a mistake. We had 14 pairs of students.

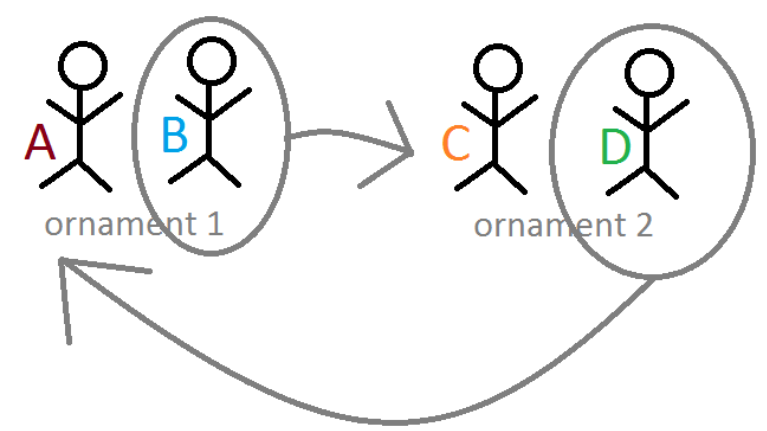

Figure 2. The work in pairs.

\subsection{Worksheets of the flower ornament}

In this article we will describe only the worksheets with flower ornaments. Worksheet A (fig. 3) and worksheet B (fig. 4) had very similar instructions. Instructions for students in the worksheet A were: ,, The ornament, which you can see in the picture, consists of some circles which are regularly organized. The ornament is not hard to construct. It is draw in a square grid and a radius of a middle circle in the ornament is 1,5 length a square's side in the square grid. A shape of the ornaments looks like a flower and so we named it a flower ornament. It is possible to see flower ornaments in 
architecture, textile design and so on."

Instructions for students of the worksheet B were: „, The ornament, which you can see in the picture, consists of some circles which are regularly organized. The ornament is not hard to construct. It is draw in a square grid and a radius of the smallest circle in the middle of the ornament, is half of square's side in the square grid. A shape of the ornaments looks like a flower and so we named it a flower ornament. It is possible to see the flower ornaments in architecture, textile design and so on."

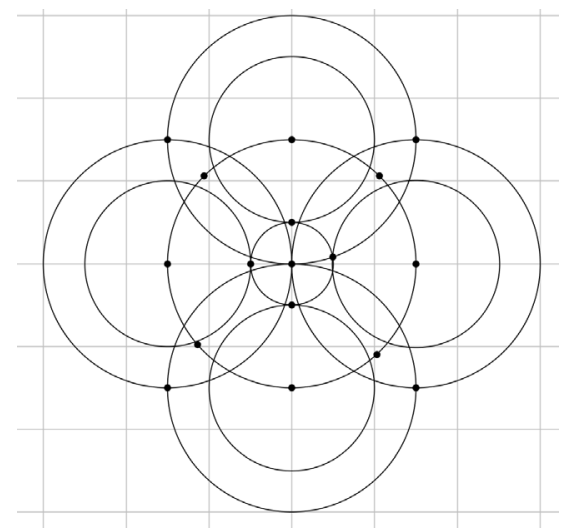

Figure 3. Worksheet A

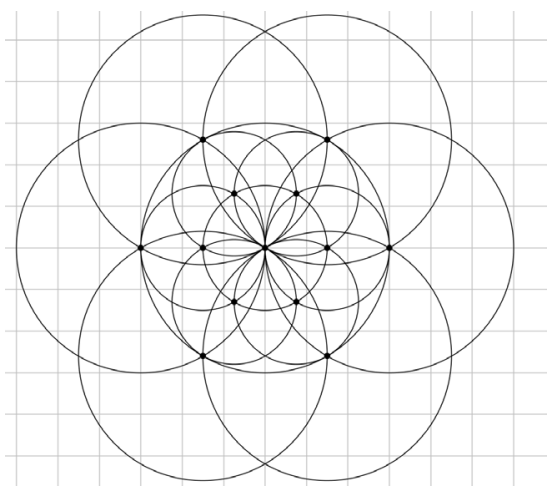

Figure 4. Worksheet B

\subsection{A-priori Analysis of the Solved Problem}

Before students solved these problems, we predict some possible ways which they can follow and communicate them to their classmates. The didactic variables are based on the students' strategies described above. We used the dichotomic variables into classes marked with labels A to $\mathrm{U}$ and we separate them in the following steps:

A. Instructions are written in items as shortcuts.

B. Instructions are written as a text.

C. Student used metrics (centimeters).

D. Student used mathematical symbolic.

E. Student used a square grid.

F. Student instructed to draw two orthogonal lines.

G. Student instructed to draw middle point $S$.

H. Student instructed to draw a bigger circle with a middle point in $S$.

I. Student instructed to draw a smaller circle with a middle point in $S$.

J. Student instructed to draw 4 (Worksheet A) or 6 (Worksheet B) smaller circles.

K. Student instructed to draw 4 (Worksheet A) or 6 (Worksheet B) bigger circles.

L. Student instructed to draw 2 circles from each of 4 points.

M. Instructions are not completely written, but there is an instruction in the text to continue as before.

N. Student instructed to divide smaller circle to 6 parts.

O. Student instructed to divide bigger circle to 6 parts.

P. Student instructed to mark intersections of three lines and circles.

Q. Student began instructions to draw a horizontal line.

R. Student instructed to draw 2 smaller circles.

S. Student instructed to draw 2 bigger circles.

T. Worksheet A

U. Worksheet B

\subsection{A-posteriori Analysis of the Solved Problem}

Results were interpreted with help of C.H.I.C. (Classification Hiérarchique Implicative et Cohésitive) which permits some quantitative analysis of pupil strategies aimed at clarifying relations among individual variables or entire classes of variables. The didactic variables were defined in a - priori analysis as construction levels and classified by binary value with 0 or 1 . Relations among the didactic variables were well displayed in graphs such as similarity tree, implicative graph and implicative tree. For the analysis we have chosen 10 students' solutions. From the similarity tree (fig. 5) we can see the following most relevant implication rules:

$$
\begin{gathered}
(\boldsymbol{J} \leftrightarrow \boldsymbol{K}) \text { a cohesion is } 90 \% \\
\boldsymbol{V} \rightarrow(\boldsymbol{J} \leftrightarrow \boldsymbol{K}) \text { a cohesion is } 86 \% \\
(\boldsymbol{L} \leftrightarrow \boldsymbol{U}) \text { a cohesion is } 86 \%
\end{gathered}
$$

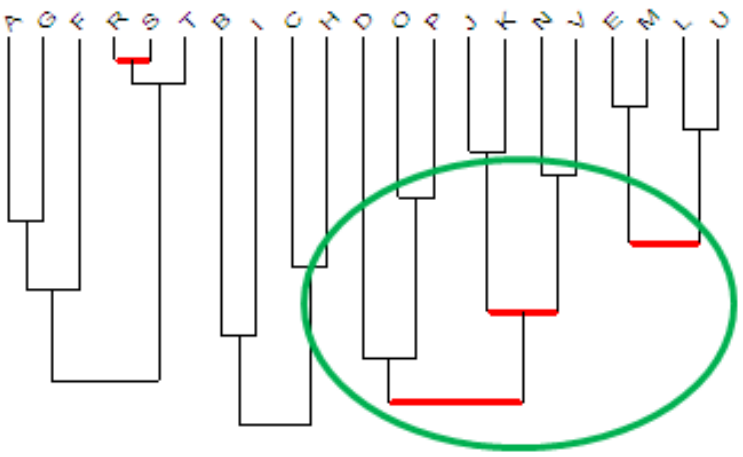

Figure 5. Similarity tree

Variables $\mathrm{J}$ and $\mathrm{K}$ mean that if a student instructed to draw 4 (Worksheet A) or 6 (Worksheet B) smaller circles, then he instructed to draw 4 (Worksheet A) or 6 (Worksheet B) bigger circles. And he did so, if he had Worksheet B with cohesion $86 \%$. There is also cohesion $86 \%$ between $\mathrm{L}$ and $\mathrm{U}$ 
what means that student with Worksheet A instructed to draw 2 circles from each of 4 points.

The Implicative graph (fig.6) is more interesting and confirms the facts that were already stated. The highest percentages are between variables $\mathrm{J}$ (Student instructed to draw 4 (Worksheet A) or 6 (Worksheet B) smaller circles) and $\mathrm{K}$ (Student instructed to draw 4 (Worksheet A) or 6 (Worksheet B) bigger circles).

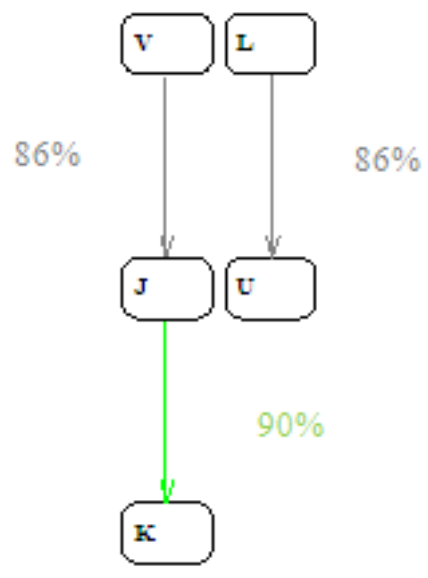

Figure 6. Implicative graph

In the Implicative tree (fig. 7) we can see the same results as in the graphs above. Together with the results from the similarity tree, the second implication graph is interesting for us. The implication tree represents also relation among $\mathrm{R}, \mathrm{S}$ and $\mathrm{T}$. The group of students who began instructions to draw a horizontal line and then they instructed to draw 2 smaller circles and 2 bigger circles.

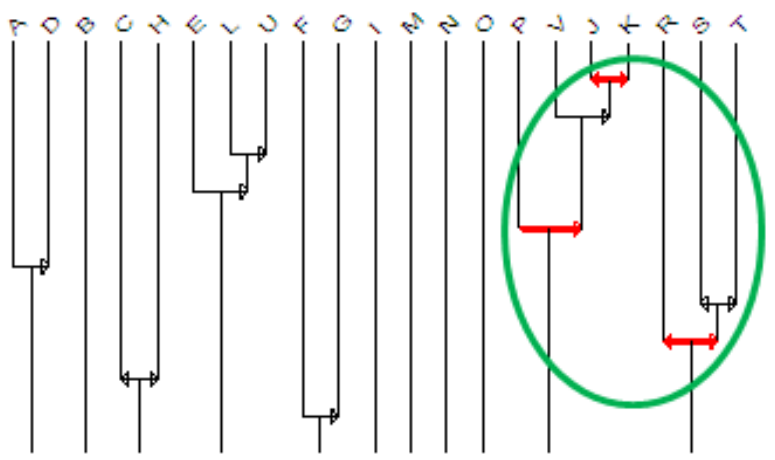

Figure 7. Implicative tree

\section{Discussion}

According the results, we can say that if students wrote his instructions in items as shortcuts or as a text, it was not determining. Also variables C, D, E: used metrics, mathematical symbolic or square grid were not important in the results. In fig. 8 is a table with used variables from $\mathrm{F}$ to $\mathrm{T}$ in a used order. S1 - S10 mean number of student. The first five of them (S1 - S5) had the worksheet A, and the second five (S6 - S10) had the worksheet B. The first step in the half of students was (variable I) to draw a smaller circle with a middle point in $S$. However, this instruction used all ten students. The instruction to draw a bigger circle with a middle point in $S$, labeled as variable $\mathrm{H}$, used 9 students. Another interesting result is that S1-S4 used only one variable L (Student instructed to draw 2 circles from each of 4 points), but S5-S10 used two variables J (Student instructed to draw 4 (Worksheet A) or 6 (Worksheet B) smaller circles.) and $\mathrm{K}$ (Student instructed to draw 4 (Worksheet A) or 6 (Worksheet B) bigger circles.). Instructions $\mathrm{R}, \mathrm{S}$ and $\mathrm{T}$ used only one student $\mathrm{S} 7$. We can see the shortest instruction is in 4 steps, we have 5 solutions and on the other hand we have the longest instruction in 8 steps, we have 2 solutions. In the fig. 9 are two correct solutions, on the left is solution from the worksheet $A$ and on the right side is correct solution from the worksheet B.

During the lesson we could see that some students wanted to be first, because they had seen the solved problem like a competition. After the lesson one student spoke about his efforts from the lesson. He liked the approach when he had to find the simplest way how to explain any construction to his classmate. All students were active in our lesson and they did the tasks. Students communicated together and were strict to keep the rules of our lesson. Not solely instructions, but also communication between students in pairs was an important part of the problem solving.

Our experience from the lesson is that a teacher can have some difficulties with students' organization. The task is better to use with students who prefer pair work and competitions in teaching and learning. We recommend using the task when we want to know what students know about instructions in geometrical constructions and how they communicate in geometry. Then we can build new knowledge on it. Or also if we want to motivate students with a competition and they have to work on speed. It is possible to make tasks more difficult or easier, if we chose more or less complicated constructions of ornaments. It our opinion the choice of ornament depends on time what we have for a lesson, students' age and their knowledge.

\begin{tabular}{|l|l|l|l|l|l|l|l|l|}
\hline & $\mathbf{1}$ & $\mathbf{2}$ & $\mathbf{3}$ & $\mathbf{4}$ & $\mathbf{5}$ & $\mathbf{6}$ & $\mathbf{7}$ & $\mathbf{8}$ \\
\hline S1 & F & G & H & L & I & & & \\
\hline S2 & H & I & F & L & & & & \\
\hline S3 & G & I & H & L & & & & \\
\hline S4 & I & H & L & M & & & & \\
\hline S5 & I & H & J & K & & & & \\
\hline S6 & I & H & N & P & J & K & & \\
\hline S7 & R & G & I & S & T & J & H & K \\
\hline S8 & F & G & I & O & J & H & N & K \\
\hline S9 & I & O & J & P & K & & & \\
\hline S10 & I & J & H & K & & & & \\
\hline
\end{tabular}

Figure 8. Table of used variables in the order. 

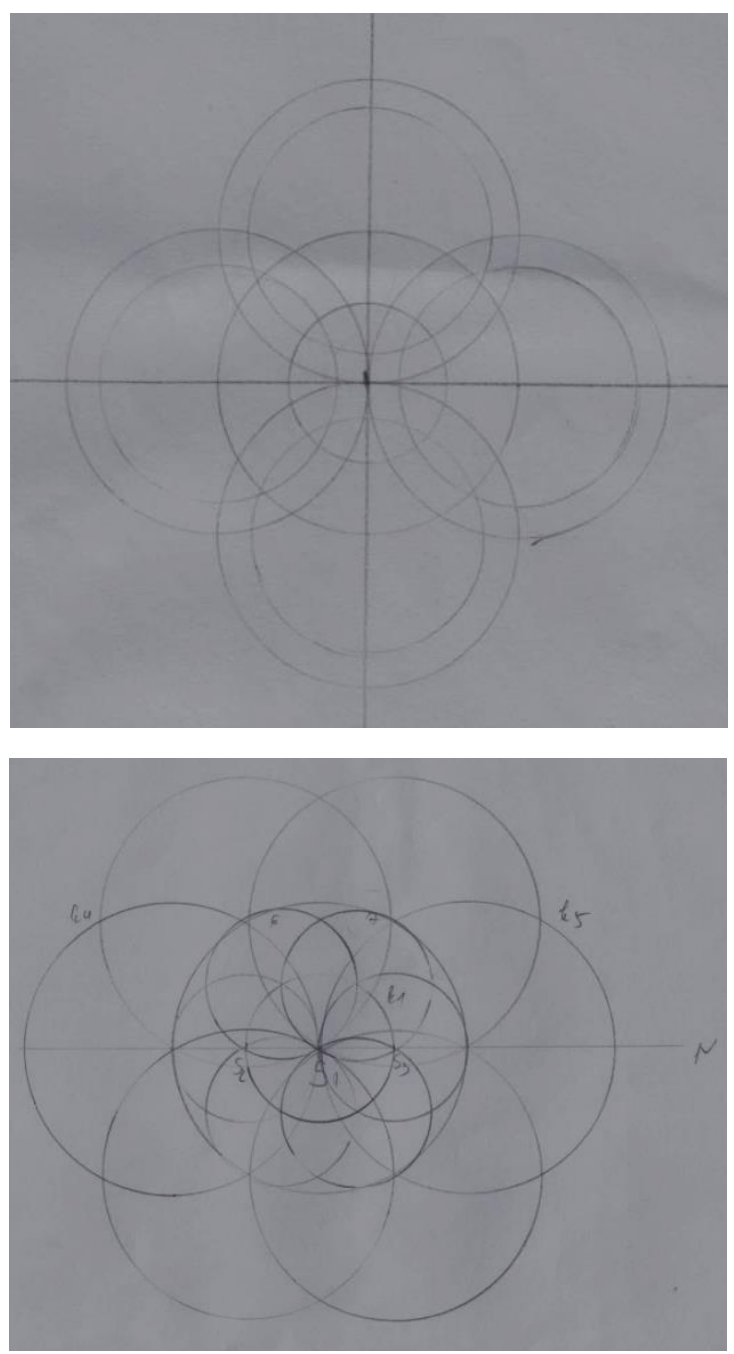

Figure 9. Correct solutions of the flowers ornament from the worksheet A and the worksheet B

\section{Conclusions}

Talk about mathematics does not come naturally. "Because mathematics is so often conveyed in symbols, oral and written, communication about mathematical ideas is not always recognized as an important part of mathematics education. Students do not necessarily talk about mathematics naturally; teachers need to help them learn how to do so." [11]

Described activity was inspiring and beneficial for a future teacher's profession. In the future, this problem will be a subject of the further research.

Through listening, talking and writing about mathematics, students are prompted to organize, re-organize and consolidate their mathematical thinking and understanding, as well as analyze, evaluate and build on the mathematical thinking and strategies of others. The use of mathematical language helps students gain insights into their own thinking and develop and express their mathematical ideas and strategies, precisely and coherently, to themselves and to others. [12]

\section{REFERENCES}

[1] Ball, D., Thames, M. H., \& Phelps, G. (2009). Content knowledge for teaching. What makes it special? Journal of Teacher Education, 59(5), 389-407.

[2] Brousseau, G. (1998). Théorie des situations didactiques. Grenoble, La Pensée sauvage, 1998.

[3] Inprasitha, M., Pattanajak, A., Inprasitha, N. (2012). A study of student's mathematical communication in teacher professional development. In Journal of Modern Education Review (p. 38-46), Volume 2, No. 1, 2012, ISSN 2155-7993.

[4] Jurcova, M. (2009). Tvorivost' vo vyučovaní a v každodennom živote. Bratislava: IRIS, 2009. ISBN 978-80-89256-42-6.

[5] Ontario Ministry of Education. (2005). The Ontario Curriculum, Grades 1 to 8: Mathematics. Toronto, ON: Queen's Printer for Ontario.

[6] Ontario Ministry of Education. (2006). A guide to effective instruction in mathematics, Kindergarten to grade 6: Volume 2 - Problem solving and communication. Toronto, ON: Queen's Printer for Ontario.

[7] Ponte, J.P. et al. (2007). Programa de Matemática do Ensino Básico. Ministério da Educação, Lisboa, 2007.

[8] Rosenstein, J.G., Caldwell, J.H., Crown, W.D. (1996). Mathematics curriculum framework. New Jersey: New Jersey State Department of Education, 1996.

[9] Sierpinska, A., Kilpatrick, J. (1998). Mathematics Education as a Research Domain: A search for Identity. Springer, Kluwer Academic Publishers, 1998.

[10] Švecová, V., Rumanová, L., Pavlovičová, G. (2014). Support of Pupil's Creative Thinking in Mathematical Education. In 5th World Conference on Educational Sciences - WCES 2013. Procedia - Social and Behavioral Sciences 116 (2014) 1715 1719, 1877-0428.

[11] Cobb, P., Wood, T., \& Yackel, E. (1993). Discourse, mathematical thinking, and classroom practice. In N. Minick, E. Forman, \& A. Stone (Eds.), Education and mind: Institutional, social, and developmental processes (pp. 91-119). New York: Oxford University Press.

[12] Vankus, P. (2008). Games based learning in teaching of mathematics at lower secondary school. In Acta Didactica Universitatis Comenianae Mathematics (p. 103-120), Issue 8. Bratislava, ISSN 1338-5186. 